\title{
DIGITALCOMMONS
} $@$ WAYNESTATE-

Wayne State University

$1-29-2019$

\section{Long-term Durability of FRP Bond in the Midwest United States for Externally-Strengthened Bridge Components}

\author{
Sasan Siavashi \\ Wayne State University, sasan.siavashi@wayne.edu \\ Christopher D. Eamon \\ Wayne State University, eamon@eng.wayne.edu \\ Abdel A. Makkawy \\ Wayne State University, abdel.makkawy@wayne.edu \\ Hwai-Chung Wu \\ Wayne State University, hcwu@eng.wayne.edu
}

Follow this and additional works at: https://digitalcommons.wayne.edu/ce_eng_frp

Part of the Civil Engineering Commons, and the Transportation Engineering Commons

\section{Recommended Citation}

Siavashi, S., Eamon, C. D., Makkawy, A. A., and Wu, H.-C. 2019. "Long-term durability of FRP bond in the Midwest United States for externally-strengthened bridge components." J. Compos. Constr. 23 (2): 05019001. https://doi.org/10.1061/(ASCE)CC.1943-5614.0000928.

This Article is brought to you for free and open access by the Civil and Environmental Engineering at DigitalCommons@WayneState. It has been accepted for inclusion in Civil and Environmental Engineering Faculty Research Publications by an authorized administrator of DigitalCommons@WayneState. 
1 Long-term Durability of FRP Bond in the Midwest United States for Externally2 Strengthened Bridge Components

3

4

5

Sasan Siavashi ${ }^{1 .}$, Christopher D. Eamon ${ }^{2}$, Abdel A. Makkawy ${ }^{3}$, and Hwai-Chung $\mathrm{Wu}^{4}$

\section{Abstract}

In this study, the bond strength of a typical FRP system subjected to long-term natural weathering in the Midwest United States is experimentally investigated, and the rate of degradation is estimated. To do this, the bond strength of an FRP system exposed to over fifteen years of weathering is determined with pull-off testing, and a relationship between strength reduction and exposure time is developed using regression analysis. For unweathered specimens, it was found that the attachment strength of the FRP system was governed by the concrete substrate, while for weathered specimens, the FRP system could detach by either a failure of the substrate, at the FRP/concrete interface, or FRP failure. It was found that a logarithmic curve best matches bond deterioration.

\section{Author Keywords:}

durability, fiber reinforced polymer (FRP), deterioration, reduction factor, bond strength

1. Ph.D. candidate, Department of Civil \& Environmental Engineering, Wayne State University, Detroit, MI, USA (corresponding author); sasan.siavashi@wayne.edu

2. Associate Professor, Department of Civil \& Environmental Engineering, Wayne State University, Detroit, MI, USA; eamon@eng.wayne.edu

3. Ph.D. candidate, Department of Civil \& Environmental Engineering, Wayne State University, Detroit, MI, USA; abdel.makkawy@wayne.edu

4. Associate Professor, Ph.D., Department of Civil \& Environmental Engineering, Wayne State University, Detroit, MI, USA; hcwu@eng.wayne.edu 


\section{Introduction}

Over the past few decades, the use of fiber reinforced polymer (FRP) materials to strengthen highway bridges has gained in popularity. Reasonable cost, speed and ease of installation, and limited disruption of the use of the structure have contributed to the adoption of FRP systems over other strengthening options.

Among the various possibilities to strengthen concrete structures with FRP, the scope of 34 this research concerns the strengthening of reinforced concrete structures using externally bonded 35 carbon FRP (CFRP) sheets. Although externally-bonded FRP has been in use for several decades and a multitude of guidelines concerning this topic exist, it remains a relatively new material in

37 civil engineering applications. As a result, limited data are available for the assessment of long38 term bond durability between the FRP and concrete substrate, a critical parameter for the system to remain effective. Although the term 'durability' is widely used, its meaning and implications 40 are often ambiguous, and the lack of information and uncertainty associated with the durability of 41 FRP systems has been recognized as an impediment to wider adoption of FRP in civil 42 infrastructure applications (Cromwell et al. 2011; ACI 2007). Durability has been defined broadly 43 as the ability of the system to resist detrimental strength, stiffness, and other undesired 44 performance changes caused by various mechanisms such as cracking, oxidation, chemical 45 degradation, and delamination, for a specific period of time and under specific load and environmental conditions (Karbhari et al. 2003; Al-Tamimi et al. 2015).

In this study, a more narrow definition of durability is considered, where the degradation 48 of bond strength between the concrete and FRP interface over time is of concern. The specific 49 environment considered is exposure of a typical highway bridge element in the State of Michigan.

50 This is a relatively harsh climate in the United States, due to the many yearly freeze-thaw cycles 
51 that civil infrastructure components experience. Subjected to this environmental exposure, the

52 focus of this study is to determine a relationship describing the loss of bond strength between a

53 typical highway bridge element and the FRP system as a function of time. For structural

54 applications, the integrity of the bond between the structure and the external FRP strengthening

55 system under adverse environmental conditions are issues of prime importance (Hollaway and

56 Leeming 1999; Mikami et al. 2015). This study is concerned not only with the deterioration of the

57 epoxy used to bond the FRP, but rather any mechanism that causes delamination of the system

58 from the concrete, as in practice, any such failure will govern the strength of the system. Thus,

59 failures may include that of the epoxy as well as that of the concrete substrate to which the FRP is

60 bonded.

61 Numerous factors affect bond durability, including the initial materials and methods used

62 for construction, the quality of workmanship, the loads imposed on the structure, the

63 implementation of a maintenance program, as well as environmental exposure (Sen 2015).

Most FRP durability information has been gathered from laboratory simulations of harsh

65 environments (Dutta and Hui 1996; Toutanji and Balaguru 1999; Karbhari et al. 2003). In these

66 studies, it was found that freeze-thaw exposures can lead to significant material degradation

67 through matrix cracking and fiber-matrix debonding as well as increased brittleness, resulting in a

68 substantial change in the damage mechanisms commonly observed under ambient conditions

69 (Dutta 1989, 1996; Haramis 2003; Karbhari 1994, 2000, 2003; Rivera and Karbhari 2002). More

70 recently, Pan et al. (2018) examined the effect of environmental conditions on the bond behavior

71 of CFRP applied to concrete and found that freeze-thaw cycles reduce fracture energy, interfacial

72 stiffness, and ultimately bond stress. In addition, a combination of freeze-thaw cycling and relative

73 humidity was found to contribute to a change in failure mode from concrete substrate failure to 
74 adhesive/concrete interfacial debonding. A similar result was found by Tuakta and Büyüköztürk

75 (2011) who examined the effect of moisture cycling on the fracture toughness of a concrete/FRP

76 bonded system. A detailed review of FRP bond durability research is given by Cabral-Fonseca et

77 al. (2018) and Böer et al. (2013), who discuss the effects of environmental and other factors on

78 bond performance. Although abundant laboratory studies are available, very few data exist

79 concerning FRP durability in actual in-situ conditions. Results from one of the longest exposure

80 periods considered is presented by Allen and Atadero (2012), who evaluated the performance of

81 FRP bond strength on a concrete bridge in Colorado 8 years after installation. Their data indicated

82 a significant reduction in mean bond strength, although some uncertainty existed with the as-

83 installed material properties. Prior to their study, the authors reported that the longest durability

84 data available considered no more than 3 years of exposure.

In design practice, the effects of environmental exposure are handled by applying specified

86 environmental reduction factors on FRP material properties. In ACI 440.2R (2017), for example,

87 the environmental reduction factor $\left(C_{E}\right)$ is applied to reduce FRP strength and strain capacity,

88 depending on the environment and fiber type. The origin of these reduction values, however, does

89 not appear to be well-documented within the ACI 440.2R commentary. Moreover, such factors

90 are intended for reduction of FRP material and resin strength rather than concrete-FRP bond

91 strength, the concern of this study. Moreover, ACI allowed a lower reduction factor if the FRP

92 system is located in an aggressive environment where prolonged exposure to high humidity,

93 freezing-and-thawing cycles, salt water, or alkalinity is expected.

ACI does recommend that FRP systems are further investigated for the effects of 
97 However, to account for possible bond degradation, AASHTO provides an upper limit to the 98 usable FRP-concrete interface shear transfer strength $\left(\tau_{\text {int }}\right)$. This limit is based on the work of 99 Naaman and Lopez (1999) and represents a lower bound of the experimental data found from the 100 bond strength of FRP-strengthened concrete specimens after subjected to a series of accelerated 101 freeze-thaw cycles. Using tests similar to those conducted by Naaman and Lopez (1999) and 102 others, degradation rates can be fundamentally calculated from the change in strength or stiffness 103 as a function of time. However, as these laboratory tests use accelerating mechanisms to artificially 104 increase the rate of degradation beyond which would be expected in the natural environment, the 105 expected in-situ deterioration is unknown.

With this background, the objectives of this study are to determine the bond strength of a 107 typical FRP system after relatively long-term (15 year) exposure to Michigan weather and to 108 estimate the rate of degradation as a function of time.

\section{Field Specimens}

Although actual service life may vary significantly, the assumed design life of a highway

111 bridge designed according to the AASHTO LRFD Bridge Design Specifications is 75 years 112 (AASHTO 2017). Here it should be noted that other sources consider different lengths of service 113 life specifically for FRP strengthening systems; for example, the British Design Manual for Roads 114 and Bridges (Volume 1, Part 16 (2002) and Part 18 (2008)), considers this to be 30 years, while 115 the UK FRP structural strengthening guideline, TR-55 (2013), considers at least a 40-year service 116 life to be appropriate. Although the collection of actual weathering data over 40 - 75 years would 117 be ideal, such information for modern, externally-bonded FRP systems does not exist. Moreover, 118 conducting such a test program may not be particularly useful, as at its conclusion, the technologies 
119 tested may be obsolete. Therefore, expected long-term effects of deterioration are generally 120 extrapolated from tests conducted over much shorter periods of time.

121 Although deterioration information is typically gathered from short term accelerated laboratory 122 testing, in this study, data from a relatively long test program which exposed specimens to actual 123 in-situ weathering up to approximately 15.5 years were obtained. These data are from two FRP124 wrapped test columns constructed by the Michigan Department of Transportation (MDOT) in July, 1251999 and tested in May, 2015. These free-standing columns were placed near the piers of an 126 existing bridge located south-east of Lansing, Michigan, a region which experiences an annual 127 average of approximately 84 freeze-thaw cycles (MDOT 2014). The columns are adjacent to a 128 secondary road of moderate traffic volume (posted speed limit of $55 \mathrm{MPH}(90 \mathrm{KPH})$ with three

129 lanes of traffic in each direction), in partial shade conditions (Figure 1). The columns were cast 130 from a standard MDOT concrete mix resulting in a compressive strength of approximately $38 \mathrm{MPa}$ 131 (5500 psi) at the time of testing. The columns were wrapped with CFRP using a hand-applied, wet 132 lay-up system and painted in accordance to the manufacturer's directions (Harichandran and 133 Baiyasi 2000; MBT 1998). The average ambient temperature in Lansing, MI in the month of 134 construction of the columns was approximately $21^{\circ} \mathrm{F}$. As specified by the manufacturer, the CFRP 135 sheets have a nominal ultimate tensile strength of $3792 \mathrm{MPa}(550 \mathrm{ksi}$,) rupture strain of $1.67 \%$, 136 and thickness of $0.165 \mathrm{~mm}(0.0065 \mathrm{in})$.

137 Bond Strength Testing

138 Prior to testing, it was found that the column faces had different degrees of observable 139 deterioration. In particular, corrosion stains from the internal steel reinforcement and other 140 discoloration was visible only on Faces 1 and 2 of the columns (see Figure 2). This is not 141 unexpected, as these faces have the highest level of exposure to adverse environmental conditions. 
142 In particular, as shown in Figure 2, these sides face the approaching vehicles from the roadway, 143 where traffic may splash rainwater, and in the winter months, deicing contaminants, primarily on 144 these column faces. Due to this observed level of increased deterioration, these three column faces 145 (Face 1 of Column 2 and Face 2 of both columns) were taken as the critical locations for further 146 consideration.

147 Bond strength was measured with a pull-off adhesion test conducted with a portable 148 automatic adhesion tester (DeFelsko 2016), in accordance with ASTM D4541-09 (ASTM 2009). 149 In this test, the end surface of a $20 \mathrm{~mm}$ (0.79 in.) diameter cylindrical metal test dolly and the FRP 150 test specimen are cleaned, then the dolly is bonded to the FRP surface with epoxy. After the epoxy 151 cures, a drill press equipped with a $23 \mathrm{~mm}(0.91$ in.) diamond-tipped core bit is used to cut the 152 FRP around the edge of the dolly, to prevent the bond of the surrounding fibers from influencing 153 test results. As detailed in ASTM D7234 (ASTM 2012), the FRP must be completely cut through, 154 slightly scoring the surface of the concrete. However, it was found that great care must be taken 155 to avoid over-cutting, as deep scoring may cause premature failure of the substrate, leading to 156 unreliable results. As suggested by Mikami et. al. 2015, scoring was limited to a depth no more 157 than $1 \mathrm{~mm}(0.04 \mathrm{in}$.). The hydraulic test machine then pulls up upon the dolly until the dolly 158 separates from the concrete specimen, and the required separation force is recorded (note a similar, 159 but alternative standard for pull-off testing, ASTM D7522, is also available).

On the test columns shown in Figures 1 and 2, 8 dollies were installed on each of the three 161 tested faces. During testing, it was found that Face 1 of Column 2 had a substantially lower bond 162 strength than the remaining column faces. This is not surprising, as it is the most exposed face, as 163 shown in Figures 1 and 2. Therefore, in addition to presenting results for all tests combined, the 164 data were also separated into two groups for further consideration: Group 1, which consists of Face 
1651 of Column 2 only (highest deterioration), and Group 2, which is composed all three faces considered; Face 1 of Column 1 and Face 2 of both columns (lower deterioration).

Several failure modes were observed. These include failure in the concrete substrate, where a thin layer of concrete separates from the specimen and remains attached to the FRP; failure at the adhesive interface, where the concrete and FRP cleanly separate; and combined concrete/adhesive failures, where failure occurs in the substrate as well as at the concrete/FRP interface (Figure 3). In general, failure modes were approximately equally split between substrate and combined substrate/FRP interface failures. Specifically, for Group 2, 50\% of the results were substrate failures, $8 \%$ were concrete/FRP failures, and 42\% were FRP failures. For Group 1, 57\% of failures were substrate failures, $14 \%$ were concrete/FRP failures and $29 \%$ were FRP failures.

Results for the columns after 15.5 years (186 months) of exposure are given in the last two rows of Table 1, where the mean and coefficient of variation (COV; standard deviation divided by mean value) of bond strength are provided.

\section{Estimation of Initial Strength}

It is of substantial interest to know not only deteriorated strength, but original strength as well, such that a rate of deterioration can be determined. As bond tests were not conducted by the DOT at the time of FRP application, prior non-deteriorated data do not exist. However, the expected as-built (i.e. non-deteriorated) pull-off strength can be determined by testing a set of recreated specimens formed using a similar mix design, FRP system, and application technique as used for the weathered columns. Such specimens can provide a reasonable approximation of unweathered system strength.

These test specimens consisted of small concrete beams with dimensions of 406 x 51 x 104 mm (16 x 2.0 x 4.1 in.), which were cast in March, 2013 using an MDOT-certified ready mix 
188 design representative of that of the field columns. Test specimens were wet-cured for 28 days 189 under an average temperature of $22{ }^{\circ} \mathrm{C}\left(72{ }^{\circ} \mathrm{F}\right)$. Average 28-day compressive strength of the test 190 specimens was found to be $39.5 \mathrm{MPa}$ (5700 psi) from 3 cylinder tests, while average compressive 191 strength of the field columns was approximately $38 \mathrm{MPa}(5500 \mathrm{psi})$. Comparing values of $\sqrt{f^{\prime}}$, 192 more relevant for substrate tensile strength (ACI 318 2014), results in similar values of 6.28 MPa 193 and 6.16 MPa for the test specimens and field columns, respectively. The test specimens were thus 194 taken as a good representation of the original column mix design.

One month after the specimens were cast, a nominally similar MBrace FRP system that 196 was recently obtained from the original manufacturer was applied on the broad (104 x $406 \mathrm{~mm}$ 197 (4.1 x 16 in.)) face of the beam specimens at a room temperature of $23^{\circ} \mathrm{C}$, as shown in Figure 4 , 198 in accordance with MDOT surface preparation and FRP application practice, which follows the 199 FRP manufacturer's instructions. One week after FRP application (where the specimens remained 200 under a constant temperature of approximately $23^{\circ} \mathrm{C}$ ), the specimens were tested for bond strength 201 in the same manner as the field columns. Mean bond strength is shown in Table 1 as the zero-time 202 result. This value is substantially higher than the bond strength found in the weathered field 203 columns at 186 months. Note that for the test specimens, bond failure in every case was found to 204 be a concrete substrate failure, indicating that the unweathered FRP bond strength is greater than 205 the substrate strength. It should be emphasized that, although effort was made to replicate the 206 existing columns and FRP system with laboratory specimens as closely as possible, the actual 207 materials, construction methods, and initial bond strength of the columns cannot be known with 208 certainty, and thus the initial strength provided by the recreated test specimens is an estimation 209 only. 
To better understand how this strength deteriorated over time, additional test specimens

211

212

213

214

215

216

217

218

219

220

221

222

223

224

225

226

227

228

229

230

231

232

were prepared to simulate in-situ weathered results at times prior to 186 months of exposure.

These additional specimens were left outdoors under exposure conditions similar to Face 1 of Column 2, and tested at 9, 14, and 28 months of exposure. Note that months 9 and 14 were used as "spot checks", where few sample tests were conducted; the longer-term 28 month results were deemed more important and thus most specimens were tested here. As shown in Table 1, mean bond strength drops steadily from 6.27 MPa (910 psi) (time $=0$; unweathered) to 4.24 $\mathrm{MPa}(615$ psi) for Group 2 and to $3.41 \mathrm{MPa}$ (495 psi) for Group 1 (at 186 months of weathering), representing a loss in strength of about $33 \%$ for Group 2 and $42 \%$ for Group 1. Also note that COV is inconsistent as well, ranging from 0.09 to 0.40 across the different weathering times considered, with no clear pattern from 0 to 28 months of weathering. However, it is clear that the test results at 186 months have the highest COV, nearly double that of any earlier times considered. A significant contributor to this increased variation at 186 months is the occurrence of different failure modes for these tests, as noted above.

\section{Characterizing Bond Loss as a Function of Time}

In the section above, bond strength is determined at several discrete points in time. However, it may be worthwhile to develop a relationship approximating bond strength reduction at any point in time. Various models have been proposed to predict deterioration rates of composites. One of the earliest was that by (Phani and Bose 1987), which concerned the degradation of flexural strength of composite laminates. The degradation mechanism for this model is assumed to be debonding at the fiber/matrix interface, and is given as: $\sigma(t)=\left(\sigma_{0}-\right.$ $\left.\sigma_{\infty}\right) \exp \left(-\frac{t}{\tau}\right)+\sigma_{\infty}$, where $\sigma_{0}$ and $\sigma_{\infty}$ are the composite strengths at time 0 and $\infty$, respectively, and $\tau$ is a characteristic time parameter dependent on temperature, which is determined from: $\frac{1}{\tau}=$ 
$233 \frac{1}{\tau_{0}} \exp \left(\frac{-E_{d}}{R T}\right)$. Here, $E_{d}$ is the activation energy, $R$ the universal gas constant, $T$ the temperature of 234 the exposure environment (Kelvin), and $\tau_{0}$ is a constant. Later, Katz and Berman (2000) studied 235 the degradation effect of high temperature on the bond between FRP bars and concrete. It was 236 found that the effect of temperature on the average bond strength could be described by: $y=$ $237 a \tanh \left[-b\left(x-k_{1} c\right)\right]+d$, where $a, b, c, d$ and $k_{1}$ are coefficients related to the bar properties, $y$ 238 represents the bond strength normalized to room temperature, and $x$ represents the temperature. 239 Although not specifically focused on bond, at about the same time, Bank et al. (2003) developed 240 a model to describe the residual strength of FRP composites over time. The model is given as: $Y$ $241=a \log (t)+b$ where $Y$ is the percent of property retention, $t$ is the exposure time, and $a$ and $b$ are 242 regression constants. This expression is perhaps the most widely used degradation model for FRP 243 bars (Davalos et. al. 2012). More recently, Davalos et. al. (2012) suggested that the percentage of 244 tensile capacity retention of FRP bars over time can be determined from: $Y=100\left(1-j t^{\alpha+1}\right)^{2}$, 245 where $\alpha$ is a material constant and $j$ is a factor accounting for temperature, solution concentration, 246 and other experimental conditions. 249 alternatives were considered including the forms proposed above, including linear, logarithmic, 250 inverse, quadratic, cubic, power, compound, logistic, growth, and exponential functions. Of these, 251 it is found that a logarithmic curve best fit the degradation of bond strength over time. When 252 selecting the best fit curve, particular attention was given to matching long-term deterioration (at 253186 months), rather than short-term (up to 28 months) changes, the latter of which are of less 254 concern for long-term structural performance. The results of all pull-off tests as a function of 255 weathering time, as well as the best-fit logarithmic curve, are plotted in Figure 5 (note time zero 
256 is taken as $t=1$ month to allow a logarithmic fit to the data, as $\log (0)$ cannot be evaluated). In the 257 figure, curves are presented separately for Groups 1 and 2, as defined earlier. Note that a 258 distinction between Group 1 and Group 2 data only appears at the $t=186$ month results, which are 259 associated with the test columns, whereas the shorter term results (0-28 months) are the same for 260 both groups. In the upper right corner of Figure 5, the curve prediction is extended to 900 months 261 (75 years) for illustration. Note that beyond 186 months, this graph represents a possible outcome 262 based on extrapolation from the logarithmic curve fit.

263 For Group 1, the best-fit regression curve predicting bond strength over time is given as:

$$
\begin{aligned}
& b=-80 \ln (t)+921 \\
& b=-0.55 \ln (t)+6.35
\end{aligned}
$$

264 whereas for Group 2, the curve is:

$$
\begin{aligned}
& b=-56 \ln (t)+911 \\
& b=-0.40 \ln (t)+6.28
\end{aligned}
$$

265 where $b$ is bond strength $(\mathrm{MPa} / \mathrm{psi})$ and $t$ time in months. For wider applicability, normalizing 266 these curves such that they provide a unitless reduction factor $(r)$ as a function of time rather than 267 direct bond strength (and $t=1$ provides a reduction factor of 1.0 to represent the initial strength), 268 results in:

$$
\begin{aligned}
& r=-0.084 \ln (t)+1.0 \quad(\text { Group } 1) \\
& r=-0.066 \ln (t)+1.0 \quad(\text { Group } 2)
\end{aligned}
$$

269 Using these curves, the resulting reduction factors are given in Table 2. The reduction factor is 270 defined here as the ratio of strength at a given time to the original strength. Predicted reduction 271 factors at 50 years were 0.46 and 0.58 , and at 75 years, were 0.43 and 0.55 , for Groups 1 and 2 , 272 respectively. 
Existing design guides provide environmental reduction factors to account for

274 environmental degradation of FRP material strength. Although not specifically meant for FRP-

275 concrete bond, these factors practically result in a reduction of system design strength regardless

276 of failure mode. As such, it may be worthwhile to examine how these existing factors compare to

277 the reduction in strength found in this study. ACI 440.R2 (ACI 2017) as well as CNR (CNR-DT

2782002013 ) suggest an environmental reduction factor of 0.85 for CFRP in an aggressive exposure

279 environment. Other design guides, such as TR55 (2013) and ISIS (2008), recognize that different

280 variabilities may be associated with different application methods. For example, TR55 (2013)

281 presents a reduction factor of 0.83 for wet lay-up applications and 0.95 for machine-controlled

282 applications. Similarly, ISIS (2008) applies a total reduction factor of 0.75 for pultruded CFRP

283 and 0.5625 for hand applied, wet lay-up CFRP (including both material strength uncertainties as

284 well as consideration of environmental degradation). As shown, the values presented in Table 2

285 are substantially more aggressive than the reduction factors of ACI, CNR, and TR55 when

286 moderate lengths of time are considered (i.e. 10 years or more). It should be noted that the factors

287 given in Table 2 account for failures beyond FRP deterioration. Rather, as discussed above, these

288 factors also account for substrate failure, which frequently controlled the bond strength of the

289 system. It should also be emphasized that these reduction factors correspond to the environment

290 in which the structure was exposed; less or more severe reductions may of course result for other

291 environmental conditions.

\section{Conclusion}

293 In this study, the bond strength of a typical FRP system exposed to approximately 15.5

294 years of in-situ weathering were analyzed, and expressions to predict bond deterioration as a 295 function of time were developed. Here bond failure is considered broadly to include any type of 
296 separation between the FRP system and the structure, and includes FRP/concrete interface failures

297 as well as failure of the concrete substrate. It was found that the resulting reduction in strength is 298 best described logarithmically, with 15.5 year strength reduction factors from $0.56-0.65$, assuming 299 that initial specimen strength is accurately modeled.

300 Due to the general lack of long-term FRP deterioration data, a significant amount of 301 additional work is recommended to better characterize bond deterioration, including consideration 302 of other climate and chemical exposure conditions, FRP system construction, and types of 303 substrate material.

304 Acknowledgement

305 Funding for this research was provided in part by the Michigan Department of Transportation, 306 support for which is gratefully acknowledged.

307 


\section{References}

310

AASHTO (American Association of State Highway and Transportation Officials). (2012) "Guide Specifications for Design of Bonded FRP Systems for Repair and Strengthening of Concrete Bridge Elements", 1st Edition, Washington, D.C.

AASHTO (American Association of State Highway and Transportation Officials). (2017) “AASHTO LRFD Bridge Design Specifications”, 7th edition, Washington, D.C.

ACI (American Concrete Institute). (2014). "Building code requirements for structural concrete." ACI 318-14, Farmington Hills, MI.

ACI (American Concrete Institute). (2007). “Causes, Evaluation, and Repair of Cracks in Concrete Structures.” ACI 224.1R, Farmington Hills, MI.

ACI (American Concrete Institute). (2007). “Report on Fiber-Reinforced Polymer (FRP) Reinforcement for Concrete Structures.” ACI 440R-07, Farmington Hills, MI.

ACI (American Concrete Institute). (2017). "Guide for the Design and Construction of Externally Bonded FRP Systems for Strengthening Concrete Structures.” ACI 440.2R-17, Farmington Hills, MI.

Al-Tamimi, A.K., Hawileh, R.A., Abdalla, J.A., Rasheed, H. A., \& Al-Mahaidi, R. (2015). "Durability of the bond between CFRP plates and concrete exposed to harsh environments. ASCE Journal of Materials in Civil Engineering, 27(9), 04014252.

Allen, D. G., \& Atadero, R. A. (2012). "Evaluating the long-term durability of externally bonded FRP via field assessments.” Journal of Composites for Construction, 16(6), 737-746. 
ASTM C805 / C805M-13 (2013), "Standard Test Method for Rebound Number of Hardened Concrete", ASTM International, West Conshohocken, PA, www.astm.org

ASTM D4541 (2009), "Standard Test Method for Pull-Off Strength of Coatings Using Portable Adhesion Testers", ASTM International, West Conshohocken, PA,www.astm.org

ASTM D7234-12 (2012), "Standard Test Method for Pull-Off Adhesion Strength of Coatings on Concrete Using Portable Pull-Off Adhesion Testers", ASTM International, West Conshohocken, PA, www.astm.org

ASTM D7522/D7522M-15 (2015), "Standard Test Method for Pull-Off Strength for FRP Laminate Systems Bonded to Concrete Substrate", ASTM International, West Conshohocken, PA, www.astm.org

Bank, L. C., Gentry, T. R., Thompson, B. P., \& Russell, J. S. (2003). “A model specification for FRP composites for civil engineering structures.", Construction and Building Materials, 17(6), 405-437.

Cromwell, J. R., Harries, K. A., \& Shahrooz, B. M. (2011). "Environmental durability of externally bonded FRP materials intended for repair of concrete structures.", Construction and Building Materials, 25(5), 2528-2539.

CNR-dt 200/2013 (2013), "guide for the design and construction of externally bonded frp systems for strengthening existing structures.”, National research council, Rome, Italy.

Davalos, J. F., Chen, Y., \& Ray, I. (2012). "Long-term durability prediction models for GFRP bars in concrete environment”. Journal of Composite Materials, 46(16), 1899-1914.

DeFelsko user manual (2016), DeFelsko Corporation, USA.

Design manual for roads and bridges, Volume 1: Highway structures: approval procedures and general design, section 3: General design Part 16: Strengthening of concrete bridge 
supports for vehicle impact using fibre reinforced polymers (2002), Highways Agency, BD 84/02, London.

Design manual for roads and bridges, Volume 1: Highway structures: approval procedures and general design, section 3: General design Part 18: Strengthening highway structures using externally bonded fibre reinforced polymer, Highways Agency (2008), BD 84/02, London.

Dolan, C. W., Tanner, J., Mukai, D., Hamilton, H. R., \& Douglas, E. (2010). "Design guidelines for durability of bonded CFRP repair/strengthening of concrete beams". National Cooperative Highway Research Program, Transportation Research Board of the National Academies, Washington, DC.

Dutta, P. K. (1989). "A theory of strength degradation of unidirectional fiber composites at low temperature. ” In Industry--University Advanced Materials Conference. II (pp. 647-662).

Dutta, P. K., \& Hui, D. (1996). "Low-temperature and freeze-thaw durability of thick composites. ” Composites Part B: Engineering, 27(3-4), 371-379.

Haramis, J. (2003). "Freeze-thaw durability of polymeric composite materials for use in civil infrastructure. " Doctorate Dissertation, Dept. of Civil Engineering, Virginia Polytechnic Institute and State University

Harichandran, R. S., \& Baiyasi, M. I. (2000). "Repair of corrosion-damaged columns using FRP wraps”, Report No. RC-1386, Michigan Department of Transportation, Lansing, Michigan.

Hollaway, L. C., \& Leeming, M. (1999). “Strengthening of reinforced concrete structures: Using externally-bonded FRP composites in structural and civil engineering. " Elsevier.

ISIS (Intelligent Sensing for Innovative Structures) (2001). “Strengthening Reinforced Concrete Structures with Externally-bonded Fibre Reinforced Polymers.” Manitoba, Canada. 
375 ISIS (Intelligent Sensing for Innovative Structures) (2008), “FRP Rehabilitation of Reinforced

376

377 378 Concrete Structures”, Design Manual 4 Version 2, Manitoba, Canada.

Karbhari, V. M., Rivera, J., \& Dutta, P. K. (2000). "Effect of short-term freeze-thaw cycling on composite confined concrete. ”Journal of composites for construction, 4(4), 191-197.

Karbhari, V. M., \& Abanilla, M. A. (2007). “Design factors, reliability, and durability prediction of wet layup carbon/epoxy used in external strengthening. "Composites Part B: Engineering, 38(1), 10-23.

Karbhari, V. M., \& Pope, G. (1994). "Impact and flexure properties of glass/vinyl ester composites in cold regions. "Journal of cold regions engineering, 8(1), 1-20, 10.1061/(ASCE)0887-381X(1994)8:1(1)

Karbhari, V. M. (2003). "Durability of FRP composites for civil infrastructure - myth, mystery or reality. " Advances in Structural Engineering, 6(3), 243-255.

Karbhari, V. M. (2004). "E-Glass/Vinylester composites in aqueous environments: effects on short-beam shear strength.” Journal of Composites for Construction, 8(2), 148-156, 10.1061/(ASCE)1090-0268(2004)8:2(148)

Karbhari, V. M., Chin, J., Hunston, D., Benmokrane, B., Juska, T., Morgan, R., \& Reynaud, D. (2003). "Durability gap analysis for fiber-reinforced polymer composites in civil infrastructure. "Journal of composites for construction, 7(3), 238-247, 10.1061/(ASCE)1090-0268(2003)7:3(238)

Katz, A., \& Berman, N. (2000). "Modeling the effect of high temperature on the bond of FRP reinforcing bars to concrete. " Cement and Concrete Composites, 22(6), 433-443.

Master Builders Technologies (MBT) (1998). "MBrace Composite Strengthening SystemEngineering Design Guidelines", Second Edition, Cleveland, Ohio. 
Mata, O. R., \& Atadero, R. A. (2013). "Evaluation of Pull-Off Tests as a FRP-Concrete Bond Testing Method in the Laboratory and Field." Practice Periodical on Structural Design and Construction, 19(2), 04014001.

Michigan Department of Transportation (MDOT). Cambridge Systematics, and Stratus Consulting (2014). "Michigan DOT Climate Vulnerability Assessment Pilot Project Final Report." Lansing, Michigan.

Mikami, C., Wu, H. C., \& Elarbi, A. (2015). "Effect of hot temperature on pull-off strength of FRP bonded concrete. ”Construction and Building Materials, 91, 180-186.

Naaman, A., Park, S. Y., \& Lopez, M. D. M. (1999). "Repair and strengthening of reinforced concrete beams using CFRP laminates"; vol. 3: behavior of beams strengthened for bending, Report No. RC-1372, Michigan Department of Transportation.Lansing, MI.

Phani, K. K., \& Bose, N. R. (1987). “Temperature dependence of hydrothermal ageing of CSMlaminate during water immersion. " Composites science and technology, 29(2), 79-87.

Rivera, J., \& Karbhari, V. M. (2002). “Cold-temperature and simultaneous aqueous environment related degradation of carbon/vinylester composites. "Composites Part B: Engineering, 33(1), 17-24.

Sen, R. (2015). "Developments in the durability of FRP-concrete bond. "Construction and Building Materials, 78, 112-125.

Toutanji, H. A., \& Balaguru, P. (1999). "Effects of freeze-thaw exposure on performance of concrete columns strengthened with advanced composites. "ACI materials journal, 96(5), 605-610.

TR55 (2013). "Design Guidance for Strengthening Concrete Structures using Fibre Composite Materials", third edition, The Concrete Society, England. 
Table 1. Bond Strength Test Results.

\begin{tabular}{cccc}
\hline $\begin{array}{c}\text { Time } \\
\text { (months) }\end{array}$ & $\begin{array}{c}\text { Mean bond } \\
\text { strength, MPa (psi) }\end{array}$ & $\begin{array}{c}\text { Sample } \\
\text { size }\end{array}$ & COV \\
\hline 0 & $6.28(910)$ & 37 & 0.23 \\
9 & $5.98(867)$ & 3 & 0.14 \\
14 & $5.89(854)$ & 4 & 0.21 \\
28 & $4.49(651)$ & 13 & 0.09 \\
\hline 186 (Group 1) & $3.41(495)$ & 7 & 0.40 \\
186 (Group 2) & $4.24(615)$ & 24 & 0.36 \\
\hline
\end{tabular}

Table 2. Bond Strength Reduction Factors.

\begin{tabular}{cccc}
\hline \multicolumn{2}{c}{ Time } & \multicolumn{2}{c}{ Reduction Factor } \\
\hline Years & Months & Group 1 & Group 2 \\
\hline 0 & 0 & 1.00 & 1.00 \\
0.75 & 9 & 0.82 & 0.85 \\
1.17 & 14 & 0.78 & 0.83 \\
2.33 & 28 & 0.72 & 0.78 \\
10 & 120 & 0.60 & 0.68 \\
15.5 & 186 & 0.56 & 0.65 \\
\hline Extrapolated: & & \\
\hline 30 & 360 & 0.51 & 0.61 \\
40 & 480 & 0.48 & 0.59 \\
50 & 600 & 0.46 & 0.58 \\
75 & 900 & 0.43 & 0.55 \\
\hline
\end{tabular}




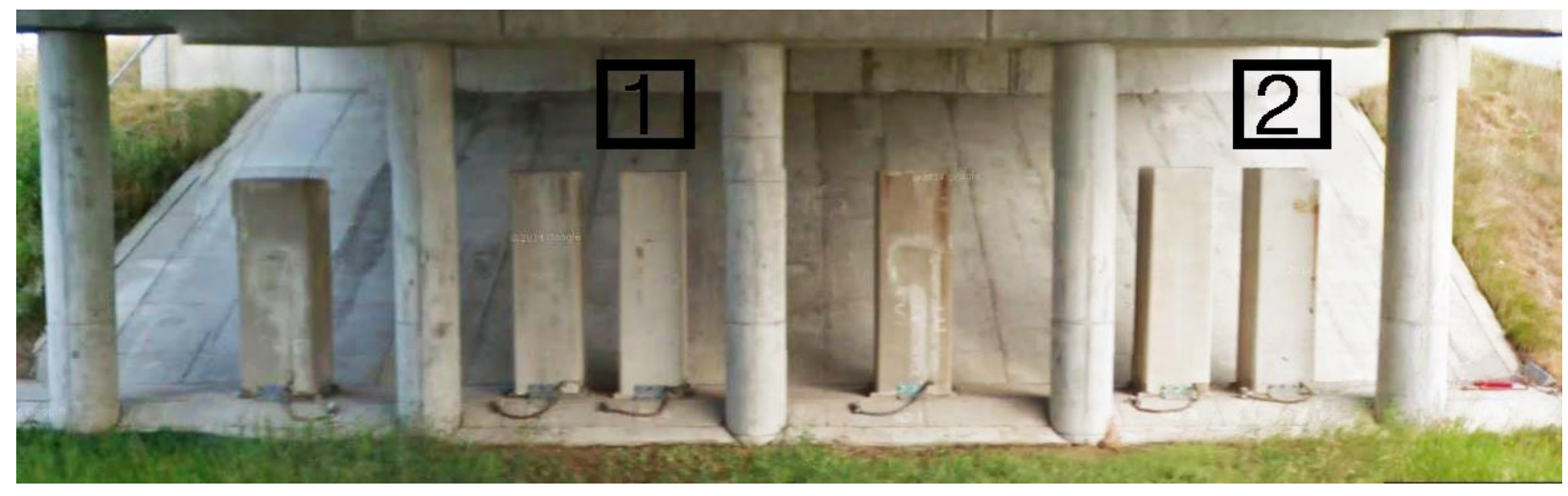

Fig. 1. Test Columns Under Westbound Interstate 96 Over Lansing Road.

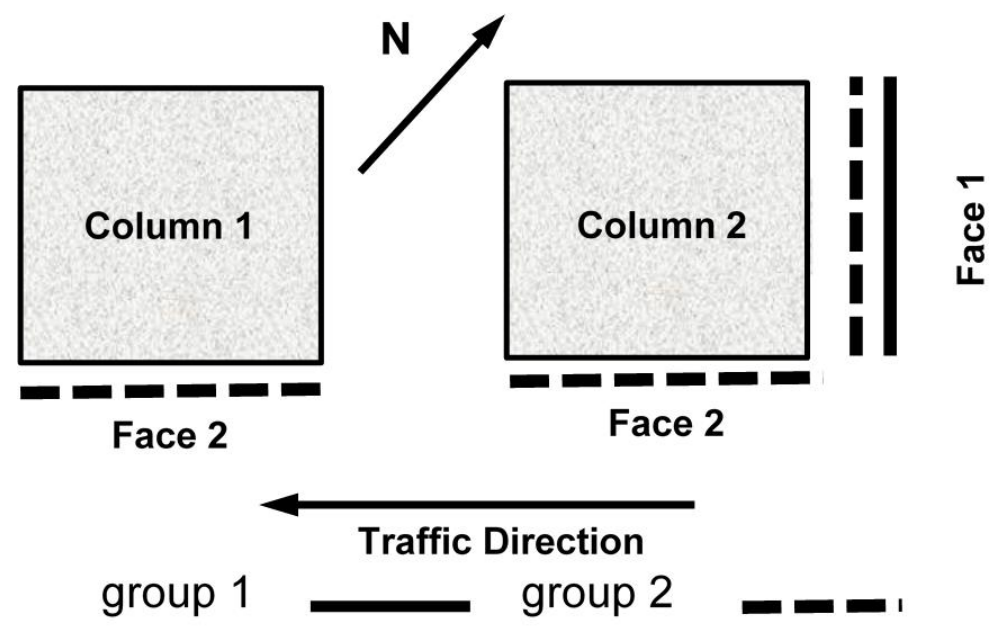

Fig. 2. Column Orientation. 

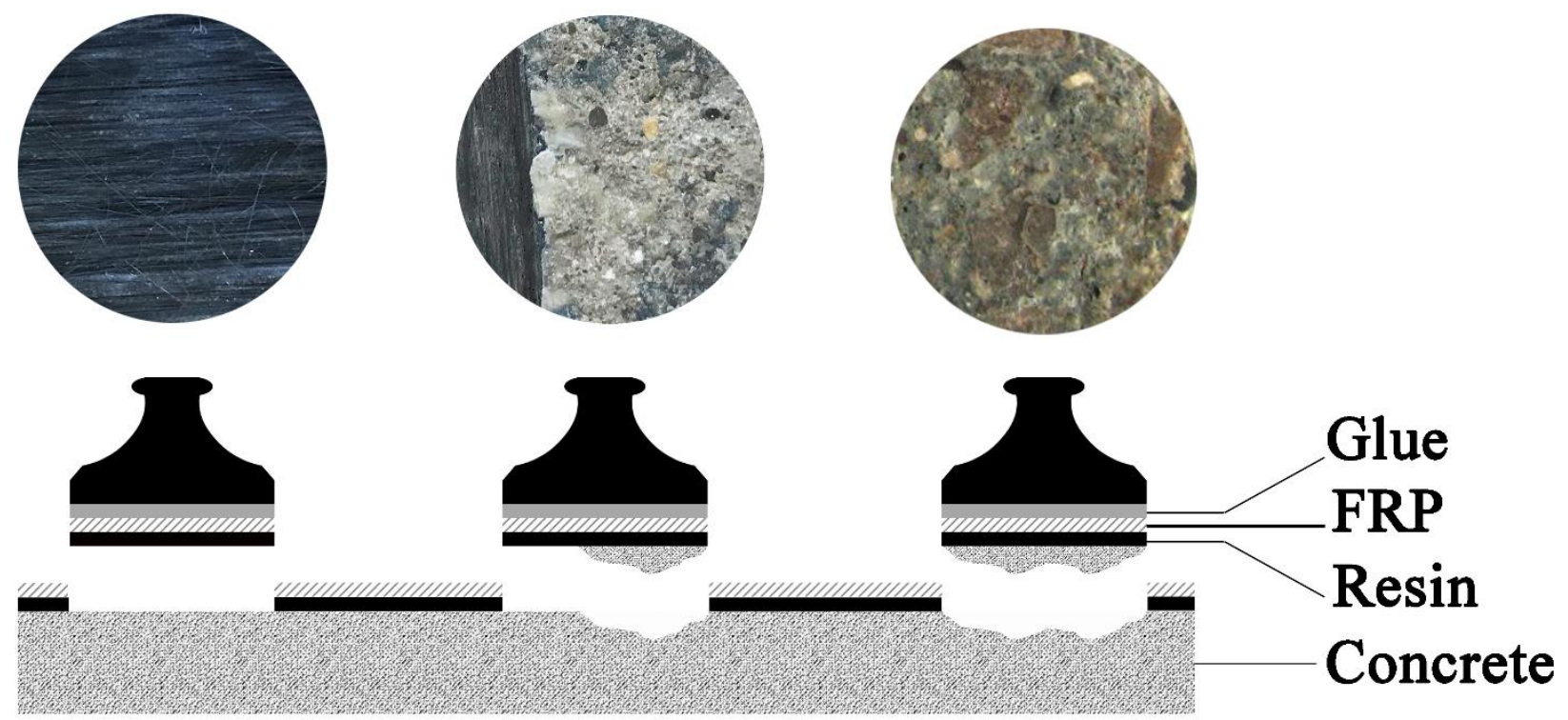

Fig. 3. Pull-off Test Failure Modes: (a) FRP adhesive failure; (b) Mixed concrete/FRP failure; (c) Concrete substrate failure

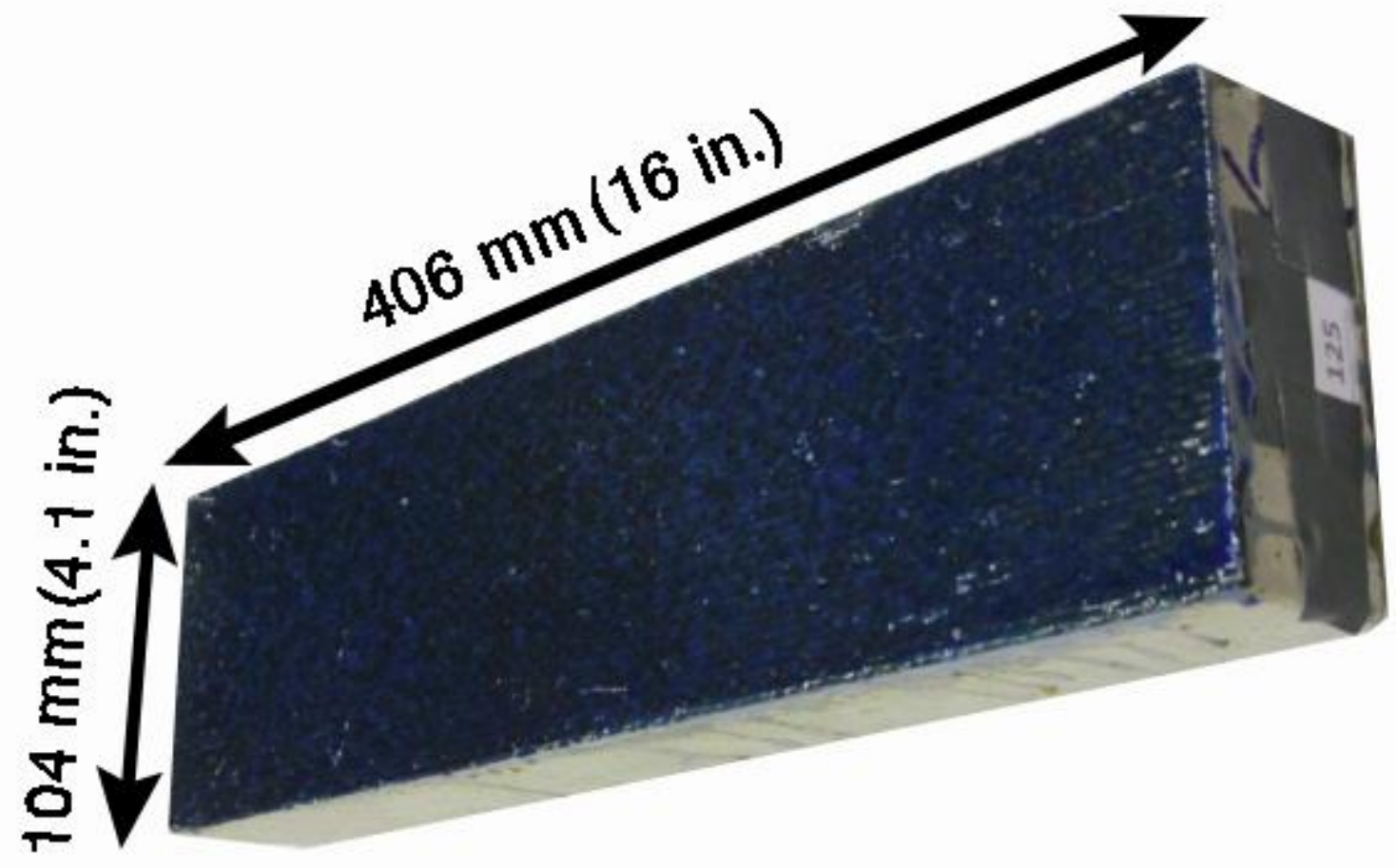

Fig. 4. Pull-off Test Specimen. 


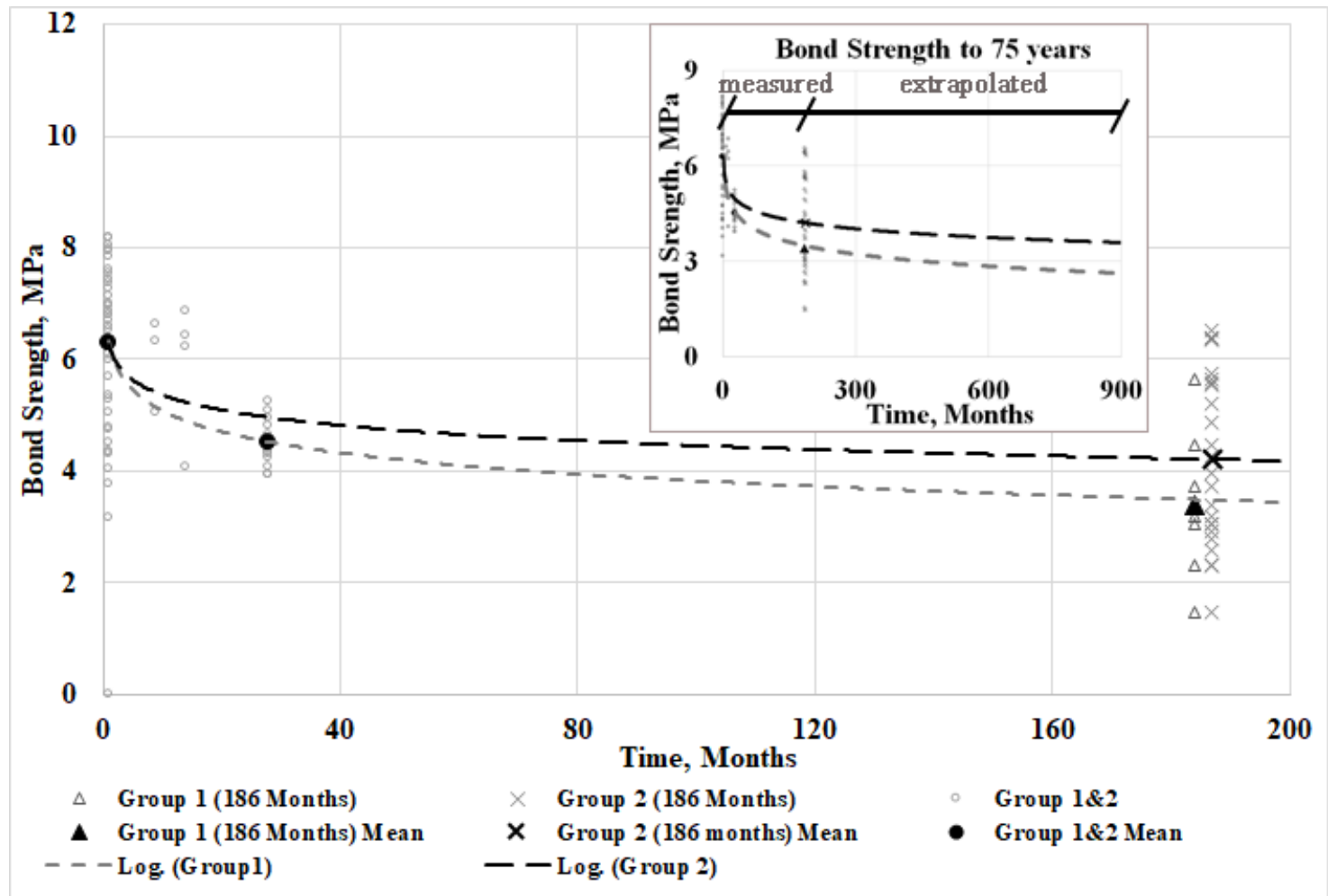

Fig. 5. Bond Strength as a Function of Weathering Time. 